\title{
Overview of the Copernicus Marine Environment Monitoring Service Products Available for the Arctic Region
}

\author{
A.L. Kholod \\ Marine Hydrophysical Institute, Russian Academy of Sciences, Sevastopol, Russian Federation \\ e-mail: antonholod@mail.ru
}

\begin{abstract}
The Copernicus Marine Environment Monitoring Service is one of six services (ocean, atmosphere, land, emergency situations, security and climate changes) launched by the European Union within the EU Earth observation program. The data in the monitoring system covers both the entire World Ocean and individual European basins. The paper reviews the products of the Copernicus Marine Service operational system available in the Arctic. At the present time this region is of the increased interest both in Russia and in the world community. The system products include information on the thermodynamic, biogeochemical and bio-optical state of the marine environment. The system products are accessed through the electronic catalog of products. Selection criteria and possibilities for searching interesting information through the interactive web-portal are given in the paper. The system products containing the data of model calculations, satellite and in situ measurement results are considered. Spatial and temporal characteristics of the products are given, information on by whom, how the product was obtained and what is its accuracy is represented. The results of the system products visualization by the integrated tools (they allow one to construct and analyze time series, profiles, horizontal and vertical sections) are shown. All the system data is publicly available to the registered users. Regular changes and updates of the system products as well as the mechanisms for accessing them take place. This information is sent to users by e-mail and is available on the news flash of the web-portal.
\end{abstract}

Keywords: Arctic, model, satellite measurements, in situ measurements, products, Copernicus Marine Environment Monitoring Service, visualization.

DOI: 10.22449/1573-160X-2017-2-25-35

(C) 2017, A.L. Kholod

(C) 2017, Physical Oceanography

Introduction. The Copernicus Marine Environment Monitoring Service (further - the Copernicus Marine Service) started to operate in April, 2015 [1]. It is based on the acquisition of satellite data on the state of the ocean and their subsequent assimilation into various mathematical models of the marine environment state. The Copernicus Marine Service operates both for the entire World Ocean as a whole and for marine basins individually. Its prototype is a system developed during the implementation of the European projects: MyOcean and MyOcean2.

Data access is carried out through an interactive web-portal (see its main page screenshot in Fig. 1). The data in the Copernicus Marine Service system is presented in the form of products. They include both the digital data and the information about the way the product was obtained and its accuracy. For this purpose, each product on the web portal has two following documents attached: a product user manual (contains a detailed description of the process of product creation, the initial data, models, variables contained in the product, the format of data representation, the mechanisms for downloading digital arrays, etc.) and a quality information document (contains information about the algorithms used to 
evaluate the data quality and a description of the data regarding which the quality of the product was assessed, as well as the accuracy estimates).

An interactive web-portal allows one to select the products of the system according to the following criteria: regional domain, parameters, temporal coverage and data type.

The selection of products is carried out in the following regional domains: Arctic Ocean, Baltic Sea, European North-West Shelf Seas, Iberia-Biscay-Ireland Regional Seas, Mediterranean Sea, Black Sea and Global Ocean. The computation for each of these regional domains is carried out by the corresponding forecast center.

It is possible to select the system products depending on the set of information they contain. The following parameters are available: temperature, salinity, current velocities, sea surface height, sea ice, wind, optics, chemistry, biology and chlorophyll.

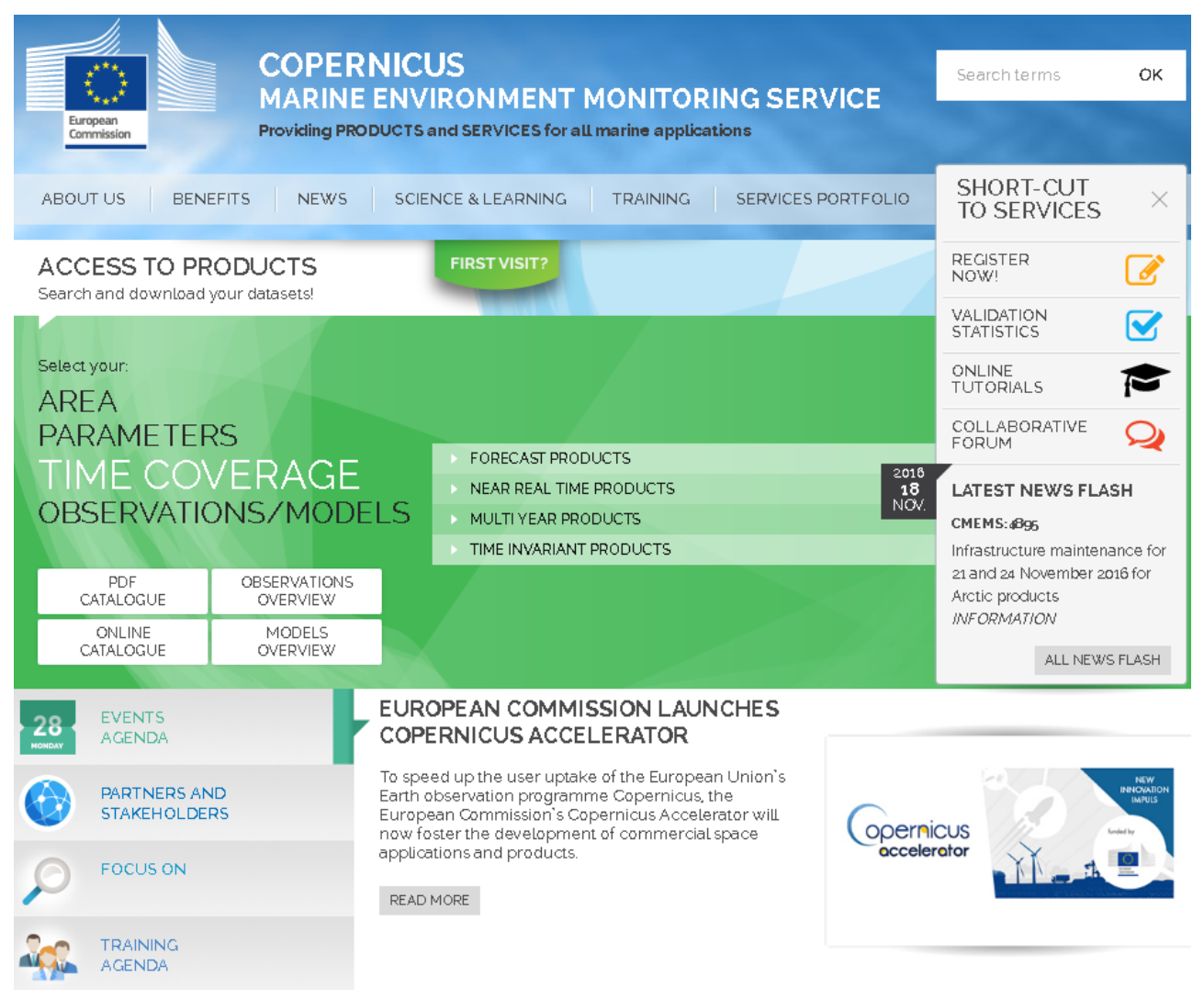

Fig. 1. The Copernicus Marine Service interactive web portal

The web portal tab TEMPORAL COVERAGE gives the possibility to select products using the time factor. There are the following categories: forecast products; near real-time products; multi-year products; time invariant products. 
According to the type of data contained, the products are divided into three groups: the results of model calculations, satellite measurements and in situ measurements.

The present article provides a brief overview of the products of the Copernicus Marine Service operational system available for the Arctic region. The division of these products according to the aforementioned criteria is presented in the table below.

The system products for the Arctic region are considered depending on the type of data contained they contain. Each product has a unique symbolic name.

\section{Amount of the System Products Available for the Arctic} Region depending on the chosen criterion

\begin{tabular}{lc}
\multicolumn{1}{c}{ Criteria } & $\begin{array}{c}\text { Amount of the products } \\
\text { available }\end{array}$ \\
\hline \multicolumn{1}{c}{ Parameters } \\
\hline Temperature & 6 \\
Salinty & 4 \\
Current velocities & 3 \\
Sea surface height & 8 \\
Ice & 7 \\
Wind & 3 \\
Optics & 5 \\
Chemistry & 3 \\
Biology & 2 \\
Chlorophyll & 7 \\
\hline \multicolumn{1}{c}{ Temporal Coverage } \\
\hline Forecast products & 2 \\
Near real-time products & 17 \\
Multi-year products & 10 \\
Time invariant products & 0 \\
\hline \multicolumn{2}{c}{ Desults of model calculations Type } \\
Satellite measurements & 4 \\
In situ measurements & 21 \\
\hline
\end{tabular}

Results of model calculations. For the Arctic region there are calculation results by the four models below available at the Copernicus Marine Service. The first two ones are working in the operational mode; the products corresponding to them are daily updated.

The product ARCTIC_ANALYSIS_FORECAST_PHYS_002_001_a contains the results of calculations by HYCOM the physical model [2 - 4], carrying out a 10-day forecast cycle. For data assimilation, which is carried out once a week, the Kalman filter is used [5,6]. At the output, the user can access the fields of 
temperature, salinity, current velocities, sea surface height, ice thickness, ice speed and mean ice cover area (Fig. 2).

The product ARCTIC_ANALYSIS_FORECAST_BIO_002_004 contains the results of calculations by the NORWECOM biological model [7] integrated with the HYCOM physical model. A 10-day forecast cycle is daily performed; the dailymean parameters of the concentration of chlorophyll, nitrates, phytoplankton, phosphates, carbon and oxygen are available to the user.

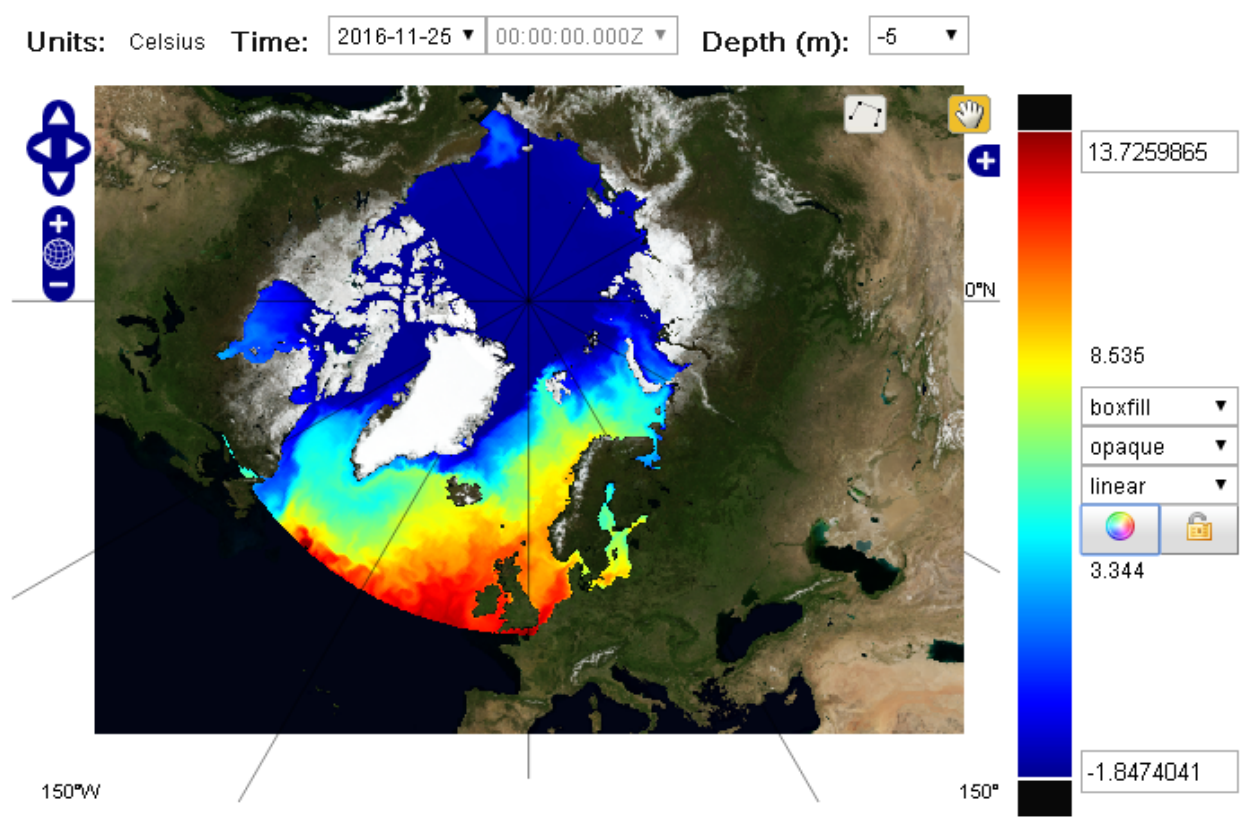

Fig. 2. An example of visualization of sea surface temperature calculation data obtained using the HYCOM physical model

The product ARCTIC_REANALYSIS_PHYS_002_003 is a retrospective analysis (reanalysis) of the monthly-mean three-dimensional physical fields of the Arctic region for the 1991 - 2010 period. The HYCOM model was used in the calculations; in situ and satellite data were assimilated applying the Kalman filter.

The product ARCTIC_REANALYSIS_BIO_002_005 contains the reanalysis data of the biological fields of the Arctic region for the 01.01.2007 15.12.2010period. The calculations were carried out using the HYCOM NORWECOM model; since 01.01.2008, the satellite data of optical scanners applying the Kalman filter had been assimilated.

All the system products, except the biological reanalysis, have a spatial resolution of $12.5 \mathrm{~km}$. The biological reanalysis data is available with a spatial resolution of $25 \mathrm{~km}$. Model calculations were carried out at the depths of 5, 30, 50, 100, 200, 400, 700, 1000, 1500, 2000, 2500 and $3000 \mathrm{~m}$.

It should be noted that the forecasting center, carrying out calculations for the entire World Ocean, also includes the Arctic region. The results of the calculation of the World Ocean state fields by the hydrodynamic model are presented in the 
product GLOBAL_ANALYSIS_FORECAST_PHY_001_024. It was obtained based on the NEMO model [8-10] V. 3.1. There is the Arakawa C-grid used; horizontal spatial resolution is $1 / 12^{\circ}(\sim 8 \mathrm{~km})$; vertical nodes are located on 50 non-equidistant horizons. The user has both daily-mean and instantaneous for every $2 \mathrm{~h}$ fields of temperature, salinity, current velocities, sea surface height, ice thickness, ice speed and mean ice cover area available (Fig. 3). The model assimilates satellite measurements of sea surface height and temperature, vertical profiles of temperature and salinity, taking into consideration the melting of icebergs. As an atmospheric effect, 3-hour atmospheric forcing fields are used. They are taken from the European Centre for Medium-Range Weather Forecasts (ECMWF) [11], which carries out a 7-day forecast cycle daily.
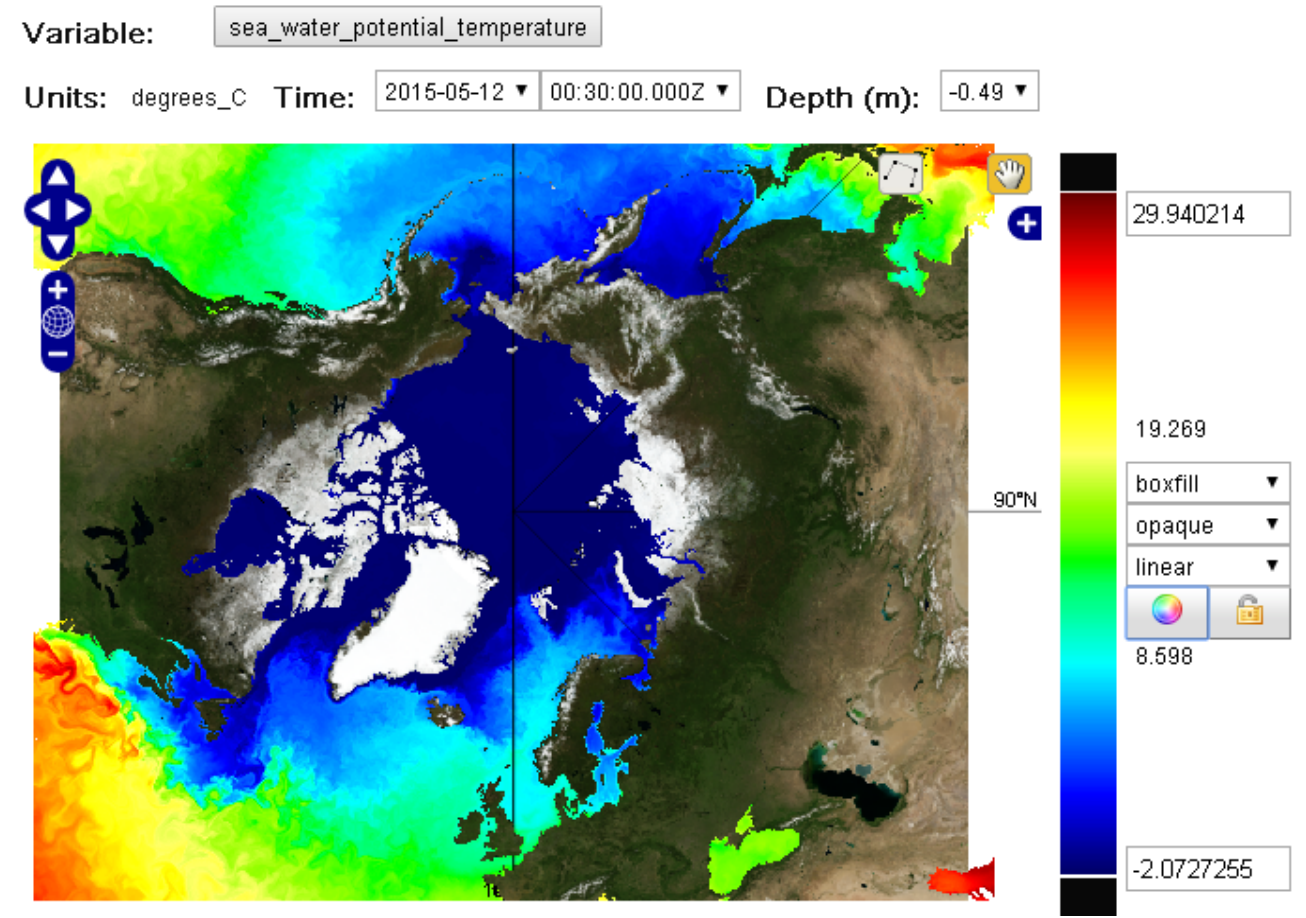

Fig. 3. An example of visualization of sea surface temperature calculation data obtained by the NEMO physical model

Satellite measurements. Temperature. The system product SST_ARC_SST_L4_NRT_OBSERVATIONS_010_008_b is created by the Norwegian Meteorological Institute (MET.NO) and contains data on the seasurface temperature of the $4^{\text {th }}$ processing level with $0.03 \times 0.03^{\circ}$ spatial resolution. For this purpose, the satellite data of radiometers in the infrared (IR) and microwave ranges are used.

Additionally for the Arctic region, the Danish Meteorological Institute (DMI) created the product SEAICE_ARC_SEAICE_L4_NRT_OBSERVATIONS_011_008, containing data on the water surface temperature and ice with $0.05 \times 0.05^{\circ}$ spatial 
resolution. The product has been developed on the basis of measurements of the $A V H R R$ radiometer installed on the MetOp-A satellite.

Both products of satellite measurements of the sea surface temperature are daily updated. An example of the visualization is shown in Fig. 4.

\section{Product id: SEAICE_ARC_SEAICE_L4_NRT_OBSERVATIONS_011_008 \\ Dataset: Arctic Sea and Ice Surface Temperature, L4, 5km daily (DMI-ARC-SEAICE_T \\ Variable: surface_temperature \\ Units: kelvin Time: $2016-03-09$ - 12:00:00.0002 Elevation: $\quad$ V}

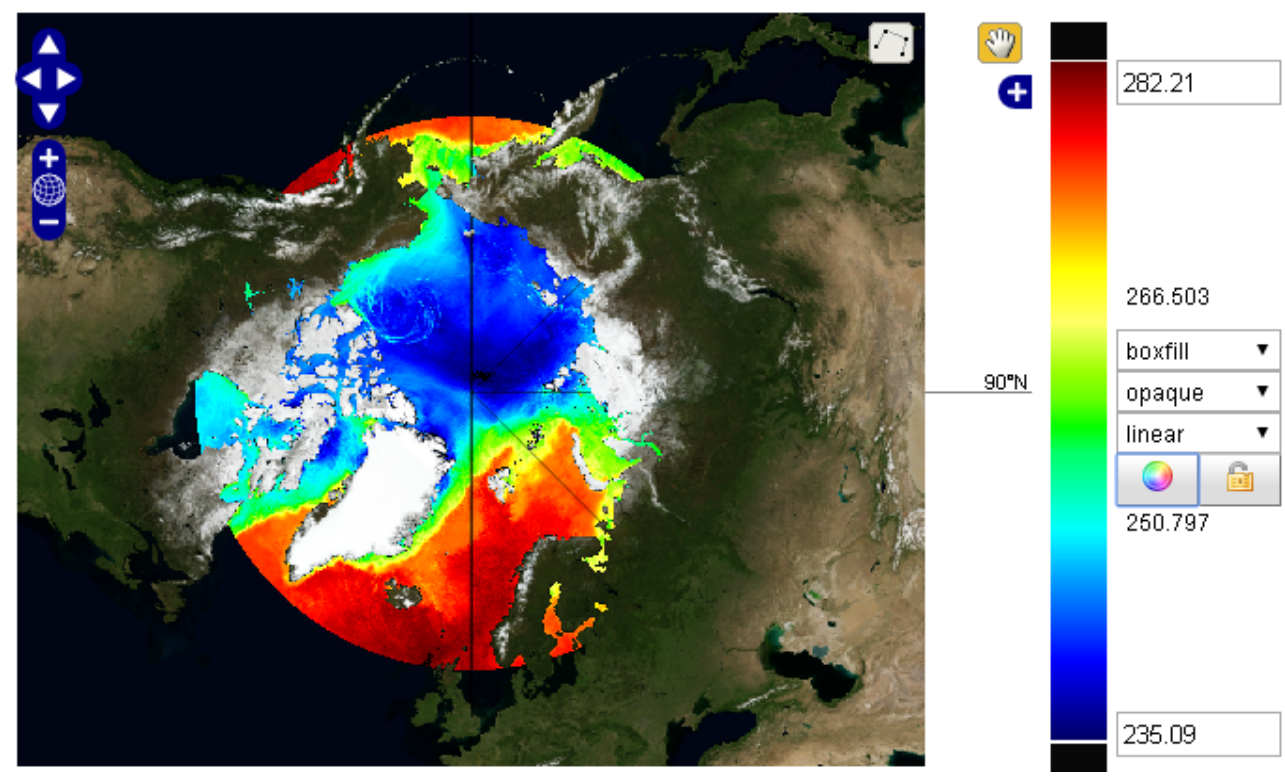

Fig. 4. An example of visualization of satellite data of sea surface temperature

Sea surface height. The Center for the Preparation and Processing of Satellite Altimetry Measurements (Toulouse, France) daily provides data on the sea surface height anomalies for the entire World Ocean and separately for the Arctic region (the products SEALEVEL_GLO_SLA_L3_NRT_OBSERVATIONS_008_017 and SEALEVEL_ARC_SLA_L3_NRT_OBSERVATIONS_008_025 respectively). The data has a $3^{\text {rd }}$ level of processing; the spatial resolution is $14 \mathrm{~km}$. There is also a product of processing of $4^{\text {th }}$ level altimetric measurements SEALEVEL_GLO_SLA_MAP_L4_NRT_OBSERVATIONS_008_026. Its spatial resolution is $0.25^{\circ}$, the data is daily updated, the daily-mean fields are available to the user.

Examples of visualization of these products are shown in Fig. 5. In addition to the operational products, the Center for the Preparation and Processing of Satellite Altimetry Measurements has created two products for the reprocessing of sea surface height anomalies. 
The $3^{\text {rd }}$

processing

level

product

SEALEVEL_GLO_SLA_L3_REP_OBSERVATIONS_008_018 contains information for the 25.09.1992 - 22.04.2015 period; the spatial resolution is $7 \mathrm{~km}$. The $4^{\text {th }}$ processing level

product SEALEVEL_GLO_SLA_MAP_L4_REP_OBSERVATIONS_008_027 includes data for the 01.01.1993-22.04.2015 period; the spatial resolution is $0.25^{\circ}$.

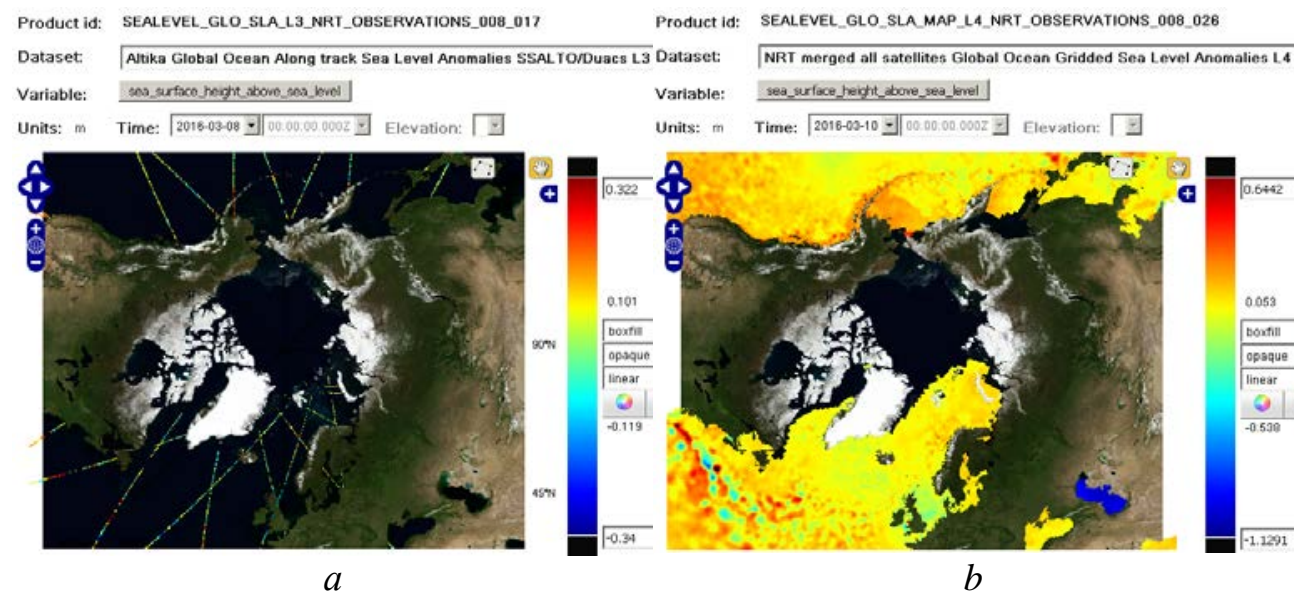

Fig. 5. An example of visualization of the results of processing satellite altimetry measurements: $a-$ tracks of satellite measurements of sea surface height; $b$ - map of sea surface height anomalies

In addition, there are time invariant products, for example, the product SEALEVEL_GLO_MDT_L4_REF_OBSERVATIONS_008_013, which contains information on the mean dynamic topography of the entire World Ocean, obtained by averaging the altimetry measurements for 7 years $(1993-1999)$; the spatial resolution is $0.25^{\circ}$. The product SEALEVEL_GLO_REF20YTO7Y_L4_OBSERVATIONS_008_034 is an addition to the mean dynamic topography for 7 years to obtain the new mean dynamic topography for 20 years (1993 - 2012); the spatial resolution is $0.25^{\circ}$.

Ice. For the Greenland waters, the operational service of the Danish Meteorological Institute issues a daily-mean map of ice concentration. This data is contained in the product SEAICE_ARC_SEAICE_L4_NRT_OBSERVATIONS_011_003, which is updated about 2 times a week (Fig. 6, a). The spatial resolution is $0.5 \mathrm{~km}$. The data are available from 01.05.2009 to the present day.

For the waters from Eastern Greenland to Novaya Zemlya the Norwegian Meteorological Institute operational service also issues daily-mean maps of ice concentration. This data is updated daily in the product SEAICE_ARC_SEAICE_L4_NRT_OBSERVATIONS_011_002, their spatial resolution is $1 \mathrm{~km}$. The maps are available from 01.04.2010 to the present day. Like the product SEAICE_ARC_SEAICE_L4_NRT_OBSERVATIONS_011_003, the data of locators with synthesized aperture installed on Envisat (till April, 2012), Radarsat and Sentinel-1 satellites, including the data of MODIS scanners and NOAA satellites in the visible and IR ranges, is used here. 
Additionally, the Danish Meteorological Institute on an irregular basis prepares data on the concentration of icebergs with the $10 \mathrm{~km}$ spatial resolution based on the use of locators with a synthesized aperture. This information is contained in the product SEAICE_ARC_SEAICE_L4_NRT_OBSERVATIONS_011_007.

The product SEAICE_ARC_SEAICE_L3_REP_OBSERVATIONS_011_010 contains data on ice drift in the Arctic region (Fig. 6, b). It is based on measurements of the ASCAT and QuikSCAT scatherometers, as well as their combination with radiometric data. Spatial resolution is $0.5^{\circ}$, the weekly and monthly mean data is available for the 01.10 .1999 - 30.04.2012 period.

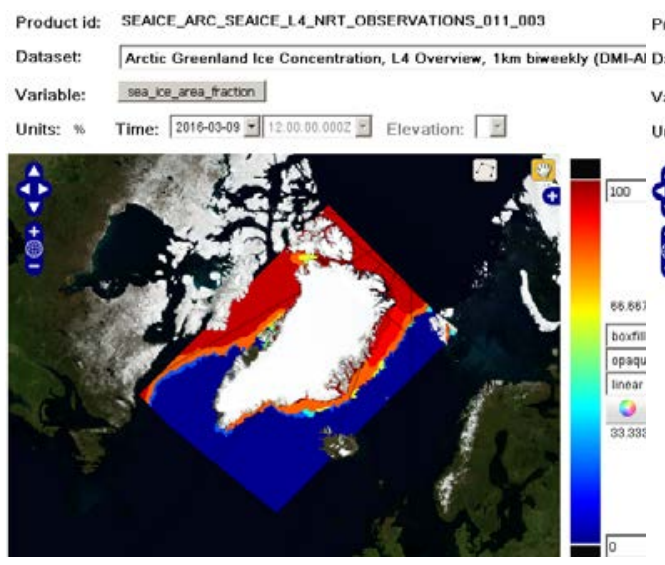

$a$
Product id: SEAICE_ARC_SEAICE_L3_REP_OBSERVAIIONS_011_010

Arctic Ocean - Sea lce - 8 days Drift, ASCAT

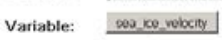

Units: m/s Time: $201204-13$ ] 0000000002 Elevation $(m): 00$

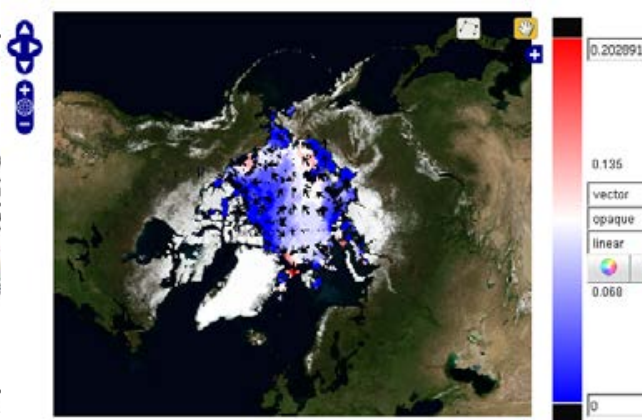

$b$

Fig. 6. An example of visualization of satellite measurement processing results: $a$ - map of ice concentration; $b$ - map of ice drift

Wind. For the entire World Ocean, including the Arctic region, the data on near-surface wind velocity is available through the Copernicus Marine Environment Monitoring Service. This data is contained in three products of the system:

- WIND_GLO_WIND_L3_NRT_OBSERVATIONS_012_002 product is developed on the basis of remote measurements of ASCAT and OSCAT scatterometers, spatial resolution makes up $0.125^{\circ}$. The data is available since 12.03.2012, it is updated every day (Fig. 7, $a$ );

- WIND_GLO_WIND_L4_NRT_OBSERVATIONS_012_004 product is developed on the basis of remote measurements of ASCAT, OSCAT scatterometers and $E C M W F$ data. Spatial resolution is $0.25^{\circ}$, temporal resolution $-6 \mathrm{~h}$. The data is available since 15.11.2012 (Fig. 7, b);

-WIND_GLO_WIND_L4_REP_OBSERVATIONS_012_003 product contains reprocessing of near-surface wind velocity fields carried out on the basis of ASCAT scatterometer data for 16.05.2007 - 16.04.2012 period. Spatial resolution is $25 \mathrm{~km}$, the data is averaged over the month. 


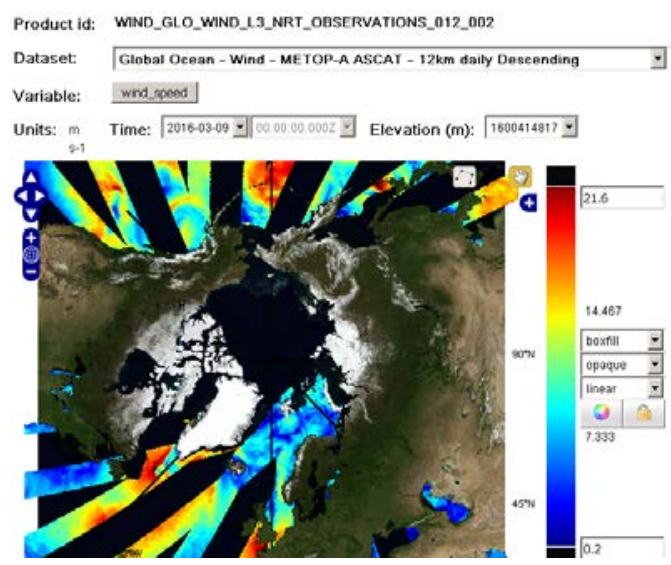

$a$

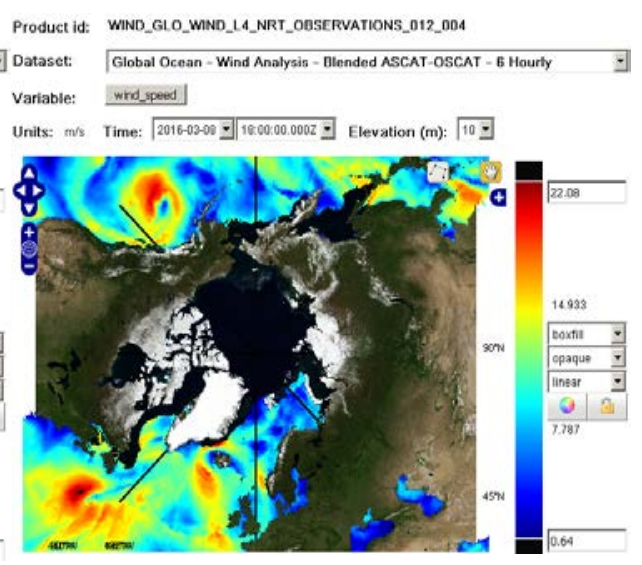

$b$

Fig. 7. An example of visualization of scatterometer satellite measurement processing results: $a$ - the third level of processing; $b$ - the fourth level of processing

Optics. Marine Laboratory (Plymouth, England) develops the products containing the data on the coefficient of diffuse light attenuation on $490 \mathrm{~nm}$ wave length as well as on sea surface reflectance for Copernicus Marine Service in the Arctic region. OCEANCOLOUR_ARC_OPTICS_L3_NRT_OBSERVATIONS_009_046_product contains daily averaged satellite data, it is updated every day and is available in near real time (NRT) mode and in delay time (DT) one. In DT mode the data is provided with a delay of several days but its quality is better due to meteorological and navigational information usage.

OCEANCOLOUR_ARC_OPTICS_L3_REP_OBSERVATIONS_009_068 product has been created on the basis of SeaWiFS, MODIS/Aqua and MERIS scanner data and contains reprocessing of the following fields: sea surface reflectance, volume absorption coefficient of radiative flux in sea water due to dissolved organic matter and non algal particles, volume absorption coefficient of radiative flux in sea water due to phytoplankton, volume backwards scattering coefficient of radiative flux in sea water due to particles, emission absorption coefficient for photosynthetically active radiation. The product includes daily averaged fields for 04.09.1997 31.07.2012 period. Spatial resolution makes up $1 \mathrm{~km}$.

Chlorophyll. Marine Laboratory in Plymouth provides the data of MODIS and VIIRS scanners on the chlorophyll concentration in the sea water in the operational mode. This data is contained in OCEANCOLOUR_ARC_CHL_L3_NRT_OBSERVATIONS_009_047 product. The data was obtained by using OC5 [12, 13] and OC488 [14] regional algorithms. The access to the data is possible in two modes - NRT and DT. DT data is provided the delay of several days and it also has a better quality due to the usage of meteorological and navigational information. Spatial resolution makes up $1.2 \mathrm{~km}$. An archive contains the data from 31.10.2013 to the present time.

OCEANCOLOUR_ARC_CHL_L3_REP_OBSERVATIONS_009_069 product is a reprocessing of chlorophyll concentration in the sea water fields performed on the basis of SeaWiFS, MODIS/Aqua and MERIS scanner data. OC5 and OC488 regional algorithms are applied. Daily averaged fields for 04.09.1997 - 31.07.2012 period are available for the users of Copernicus Marine Service. 
In situ measurements. There are two products for the Arctic region containing the information on in situ measurements. Продукт INSITU_ARC_NRT_OBSERVATIONS_013_031 product is updated daily and contains the data of in situ measurements carried out in NRT mode (delay time is up to $48 \mathrm{~h}$, automatic data quality control is performed at that). An archive contains the data from 10.10.2010 to the present time. Measurement data is provided by members of Arctic ROOS community [15]. The product includes information on temperature, salinity, components of current velocities, sea surface level, chlorophyll and oxygen.

INSITU_ARC_TS_REP_OBSERVATIONS_013_037 product contains the archived data of temperature and salinity in situ measurements fro 10.10.1990 31.12.2013 period. The data is provided by the members of Arctic ROOS and SeaDataNet NODCs communities.

Conclusions. Copernicus Marine Environment Monitoring Service has rather wide range of operational system products for the Arctic region. This data is freely available and is regularly updated and supplemented. It is important to point out that each product of the system is described in detail in the user manual and the data on its accuracy is also given. The system has a user-friendly toolkit for the data visualization and analysis. Copernicus Sea Service regularly reports on updates and changes in the system products as well as on mechanisms for accessing them. This information is sent to the users by e-mail and is available in the news feed of web portal.

Acknowledgements. The study is carried out within the framework of the State Order No. 0827-2014-0011 "The research of regularities of marine environment condition changes on the basis of operational observations and the data of marine area condition nowcast, forecast and reanalysis system" ("Operative oceanography” code).

\section{REFERENCES}

1. Copernicus. 2016. Marine Environment Monitoring Service. [online] Available at: http://marine.copernicus.eu [Accessed 25 November 2016].

2. Bleck, R. and Boudra, D.B., 1981. Initial Testing of a Numerical Ocean Circulation Model Using a Hybrid (Quasi-Isopycnic) Vertical Coordinate. J. Phys. Oceanogr., [e-journal] 11(6), pp. 755-770. doi.org/10.1175/1520-0485(1981)011<0755:ITOANO>2.0.CO;2

3. Halliwell, G., Bleck, R. and Chassignet, E., 1998. Atlantic Ocean Simulations Performed Using a New Hybrid-Coordinate Ocean Model. EOS, Trans. AGU, Fall 1998 AGU meeting.

4. Bleck, R., 2002. An Oceanic General Circulation Model Framed in Hybrid IsopycnicCartesian Coordinates. Ocean Modelling, [e-journal] 4(1), pp. 55-88. doi:10.1016/S14635003(01)00012-9

5. Kalman, R.E., 1960. A New Approach to Linear Filtering and Prediction Problems. J. Basic Eng., [e-journal] 82(1), pp. 35-45. doi:10.1115/1.3662552

6. Evensen, G., 2003. The Ensemble Kalman Filter: Theoretical Formulation and Practical Implementation. Ocean Dynamics, [e-journal] 53(4), pp. 343-367. doi:10.1007/s10236-0030036-9

7. Aksnes, D.L., Ulvestad, K.B., Baliño, B.M., Berntsen, J., Egge, J.K. and Svendsen, E., 1995. Ecological Modelling in Coastal Waters: Towards Predictive Physical-Chemical-Biological Simulation Models. Ophelia, [e-journal] 41(1), pp. 5-36. doi:10.1080/00785236.1995.10422035 
8. NEMO. Community Ocean Model. [online] Available at: http://www.nemo-ocean.eu [Accessed 2 November 2016].

9. Madec, G., 2008. NEMO Ocean Engine. Note du Pôle de modélisation. Technical Report. [e-book] France: Institut Pierre-Simon Laplace. No. 27. Available at: https://www.nemoocean.eu/doc/node1.html [Accessed 5 November 2016].

10. Dombrowsky, E., Bertino, L., Chanut, J., Drillet, Y., Huess, V., Misyuk, A., Siddorn, J. and Tonani, M., 2012. NEMO in MyOcean Monitoring and Forecasting Centres (MFCs). Mercator Ocean Quarterly Newsletter, [e-journal] 46, pp. 31-45. Available at: https://www.mercator-ocean.fr/sciences-publications/mercator-ocean-journal/newsletter-46nemo-myocean/ [Accessed 5 November 2016].

11. ECMWF. [online] Available at: http://www.ecmwf.int [Accessed 7 November 2016].

12. Gohin, F., Druon, J.N. and Lampert, L., 2002. A Five Channel Chlorophyll Concentration Algorithm Applied to SeaWiFS Data Processed by SeaDAS in Coastal Waters. Int. J. Rem. Sens., [e-journal] 23(8), pp. 1639-1661. doi:10.1080/01431160110071879

13. O'Reilly, J.E., Maritorena, S., Mitchell, B.G., Siegel, D.A., Carder, K.L., Garver, S.A., Kahru, M. and McClain, C., 1998. Ocean Color Chlorophyll Algorithms for SeaWiFS. J. Geophys. Res., [e-journal] 103(C11), pp. 24937-24953. doi:10.1029/98JC02160

14. McClain, C.R., Evans, R.H., Brown, J.W. and Darzi, M., 1995. SeaWiFS Quality Control Masks and Flags: Initial Algorithms and Implementation Strategy. In: NASA Tech. Memo. 104566. SeaWiFS Algorithms, Part I, vol. 28. Greenbelt, MD: NASA Goddard Space Flight Center, pp. 3-7. Available at: https://oceancolor.gsfc.nasa.gov/docs/technical/seawifs_reports/prelaunch/PreLVol28.pdf [Accessed 7 November 2016].

15. Arctic Regional Ocean Observing System. [online] Available at: http://arctic-roos.org [Accessed 17 November 2016]. 